\title{
Dr William Smellie (1697-1763), the master of British midwifery
}

\author{
Peter M Dunn
}

William Smellie, outstanding obstetric clinician and teacher, was born in Lanark, Scotland, in 1697, the only child of Archibald and Sarah Smellie. He obtained his early education at Lanark Grammar School and was then apprenticed to a local apothecary, William Inglis. Afterwards he may have served as a surgeon's mate at sea for two years. $\mathrm{He}$ may also have studied in Glasgow, for many years later in 1745 he was granted an MD by Glasgow University.

In 1722 he entered medical practice in Lanark. Midwifery became a special interest and he kept careful records of all his cases. Nineteen years later, wishing to improve his knowledge of forceps delivery, he travelled south to London, acquired a house in Pall Mall, and started to practise in the poorer areas of the city. He also taught midwifery, using life-like models that he had made himself. Ten years later he was able to claim that he had given 280 courses (each of 12 lectures) to more than 900 pupils (excluding female students) and had taught in the home at the delivery of some 1150 women. One of his first pupils was William Hunter, who was also to achieve distinction in obstetrics. ${ }^{12}$

Smellie has been described as a man of great wisdom, skill, and sound judgment. At the same time he was also described as being canny, cautious, and kindly. He had many friends but few intimates. He was not acquisitive, his one ambition being to gain respect and recognition for his work. He shunned publicity and did not respond to critics. His hobbies included carving, painting, drawing and he played the violoncello, the organ, and the recorder.

Smellie strongly believed in natural childbirth and non-interference whenever possible. He appreciated the importance of the upright posture, mobility, and intact membranes during the first stage of labour. He was an accurate observer of nature and in particular studied the mechanism of normal labour. His was the first accurate description of the passage of the fetal head through the female pelvis, thereby laying the foundation of scientific obstetrics. In particular, he recognised that the transverse diameter of the pelvis was greatest at the brim and least at the outlet. $\mathrm{He}$ was the first to describe the diagonal conjugate of the pelvis and use it as a clinical

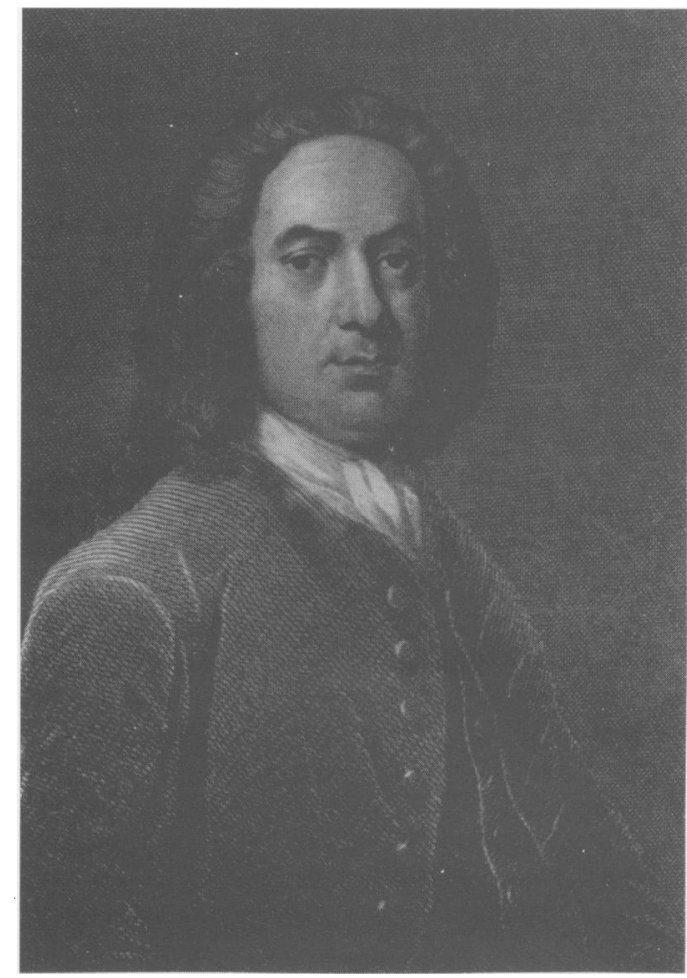

William Smellie, MD, based on a 1719 self portrait in the Royal College of Physicians, Edinburgh.

tool. The forceps he designed, the best of his day, incorporated two important innovations, the Smellie lock and the pelvic curve. He developed the essential rules for the use of forceps and perfected the manoeuvre for the management of breech deliveries previously ascribed to Mauriceau. He was also the first to use forceps to deliver the after-coming head, the first to describe uterine dystocia due to hour-glass contraction, and the first to resuscitate a newborn infant by insufflation of the lungs.

Smellie collated his extensive experience into a Treatise on the Theory and Practice of Midwifery, published in $1752 .{ }^{3}$ Second and third volumes, based on 531 case histories, followed in 1754 and 1764 , with the help of his friend Dr Tobias Smollett. These three volumes were by far the finest obstetric text of the day, and are still a treat to read. The Treatise went through nine English editions in the United Kingdom and North America and 
was translated into French, German, and Dutch. Smellie's second great work, a set of anatomical tables, prepared with the help of Jan van Rymsdyck and Peter Camper, was published in $1754 .^{4}$

The following sections from his Treatise discuss his management of the umbilical cord at delivery, the resuscitation of a stillborn infant, and the effect of tight umbilical binders.

\section{On fetal adaptation at birth:}

'The child being delivered, ought to be kept warm beneath the bed-clothes, or immediately covered with a warmed flannel or linen cloth; if it cries and breathes, the umbilical cord may be tied and cut, and the child delivered to the nurse without delay; but if the air does not immediately rush into the lungs, and the circulation continues between it and the placenta, the operation of tying and cutting must be delayed, and everything tried to stimulate and sometimes to give pain. ... Whatever augments the circulating force, promotes respiration; and as this increases, the circulation grows stronger, so that they mutually assist each other.'

'If the child and placenta are both delivered suddenly, or the last immediately after the first; and if the child, though alive, does not yet breathe, the blood may be felt circulating sometimes slowly, at other times with great force, through the arteries of the funis to the placenta, and from thence back again to the child, along the umbilical vein. When the vessels are slightly pressed, the arteries swell between the pressure and the child, while the vein grows turgid between that and the placenta, from the surface of which no blood is observed to flow, although it be lying in a basin among warm water. As the child begins to breathe, the circulation, though it was weak before, immediately grows stronger and stronger; and then in a few minutes the pulsation in the navelstring becomes more languid, and at last entirely stops.'

'The funis being separated, and the child committed to the nurse, the next care is to deliver the placenta and membranes ... if there is no danger from a flooding, the woman may be allowed to rest a little, in order to recover from the fatigue she has undergone, and that the uterus may in contracting have time to squeeze and separate the placenta from its inner surface; during which pause also, about one, two, or three cups full of blood are discharged through the funis from the vessels of the placenta, which is thus diminished in bulk, so that the womb may be more contracted; and this is the reason for applying one ligature only upon the cord.'

\section{On resuscitation of a stillborn infant:}

'In the year 1749 , I attended a woman in labour, and the navel-string presenting with the arm, I delivered the child by the feet. From the pulsation in the arteries of the funis, I knew it was alive; but I found great difficulty in delivering the head, and was obliged to rest several times before I could effect it; so that the pulsation ceased, and the child seemed to be dead, after all the common efforts were used for its recovery. Nevertheless, I inflated the lungs, by blowing into the mouth through a female catheter, and the child gave one gasp; upon which I repeated the inflation at several intervals, until the child began to breathe; and it actually recovered.'

\section{On tight umbilical binders:}

'I have been called several times, where I found the uneasiness of the children proceeded from too tight dressings; and by observing this circumstance in time, the danger was prevented by dressing them looser ... About two years ago, I was called to see a child, on the fourth day after delivery, and was told that it heaved, and had an oppression at its breast. The nurse undressed the child; and the clothes did not seem tight, but I observed the bandage on the navel appeared very tight. This I ordered to be unrolled; and plainly perceived that it was the cause of the disorder; for the child immediately breathed with greater freedom, and did very well in the sequel.'

Smellie's success is all the more remarkable in that it was gained without the aid of powerful friends or the advantages of a hospital clinic. Besides his scientific achievements, he helped to overcome the existing prejudice against male midwives and the use of forceps, and he improved relations with the midwives. But Smellie was troubled with asthma and in 1759 he made over his class, museum, and teaching aids to Dr John Harvie, and returned to Scotland with his wife Eupham Borland, whom he had married in 1724. There had been no family. Their last years were spent at their home, Smyllum, near Lanark. Smellie died there aged 66 in 1763, and his wife in 1769, Both were buried at the Kirk of St Kentigen nearby.

1 Wall LL. William Smellie (1697-1763): the father of scientific obstetrics. In: Medical heritage. Philadelphia: WB Saunders Co, 1986: 158-67.

2 Spencer HR. The history of British midwifery from 1650 to 1800 London: John Bale, 1927: 43-60.

$3 \mathrm{McClintock} \mathrm{AH}$, ed. Smellie's treatise on the theory and practice of midwifery. Vols I, II, \& III. London: The New Sydenham Society, 1876-78.

4 Smellie W. A set of anatomical tables with explanations and an abridgement of the practice of midwifery. London: Charles Elliot \& Co, 1754 . 